\title{
The investigation of the role of the facet joint angle in the development of L5-S1 spondylolysis in young men
}

\author{
Ahmet Eroğlu, ${ }^{1}$ Enes Sarr, ${ }^{2}$ Ferhat Cüce, ${ }^{3}$ Fatih Tok, ${ }^{4}$ Cem Atabey, ${ }^{5}$ Bülent Düz ${ }^{6}$ \\ ${ }^{1}$ Department of Neurosurgery, Van Military Hospital, Van, Turkey \\ ${ }^{2}$ Department of Orthopedics and Traumatology, Aksaz Military Hospital, Muğla, Turkey \\ ${ }^{3}$ Department of Radiology, Mevki Military Hospital, Ankara, Turkey \\ ${ }^{4}$ Department of Physical Medicine and Rehabilitation, TSK Rehabilitation Center, Ankara, Turkey \\ ${ }^{5}$ Department of Neurosurgery, Mevki Military Hospital, Ankara, Turkey \\ ${ }^{6}$ Department of Neurosurgery, İstanbul Sultan Abdülhamid Han Training and Research Hospital, İstanbul, Turkey
}

Received: March 2016 Accepted: August 2016

\section{ABSTRACT}

Objectives: This study aims to evaluate facet tropism in younger patients with lumbar spondylolysis and to investigate the role of facet tropism in the development of spondylolysis.

Patients and methods: Between February 2013 and December 2015, a total of 102 male patients with bilateral L5 pars defect including 53 with spondylolysis and 49 control subjects were included in this case-control study. The facet joint angles were measured bilaterally and axially at the level of L3-4, L4-5, L5-S1 using computed tomography (CT). The classification was made as follows: A difference between two reciprocal facet joint angles of $<6^{\circ}$ indicated no tropism, $6^{\circ}-12^{\circ}$ indicated moderate tropism, and $>12^{\circ}$ indicated severe tropism.

Results: A total of 612 angles including 318 facet joint angles from 53 patients with spondylolysis and 294 facet joint angles from 49 control subjects were measured. L3-4 measurements in the control group showed no tropism in $87.8 \%(\mathrm{n}=43)$, moderate tropism in $12.2 \%(\mathrm{n}=6)$, and severe tropism in $0 \%(\mathrm{n}=0)$. L4-5 measurements in control group showed no tropism in $79.6 \%(\mathrm{n}=39)$, moderate tropism in $20.4 \%(\mathrm{n}=10)$, and severe tropism in $0 \%(\mathrm{n}=0)$. L5-S1 measurements in the control group showed no tropism in $69.4 \%$ ( $\mathrm{n}=34$ ), moderate tropism in $28.6 \%$ $(\mathrm{n}=14)$, and severe tropism in $2.0 \%(\mathrm{n}=1)$. The mean facet joint angles in the spondylosis group were $32.9 \pm 5.1^{\circ}, 37.5 \pm 5.4^{\circ}$, and $41.2 \pm 7.8^{\circ}$ at the levels of L3-4, L4-5, and L5-S1, respectively. The mean facet joint angles of the control group were $33.2 \pm 5.7^{\circ}, 39.7 \pm 4.9^{\circ}$, and $42.2 \pm 4.9^{\circ}$ at the levels of L3-4, L4-5, and L5-S1, respectively, indicating no significant difference between the right and left mean facet joint angles between the groups ( $>0.05)$. The frequency of facet tropism and the difference between right and left facet joint angles for all three levels were significantly higher in the spondylolysis group $(\mathrm{p}<0.05)$. Facet tropism at the level of L5-S1 was significantly more frequent than facet tropism at L3-4 level $(\mathrm{p}<0.05)$.

Conclusion: Our study results show that the rate of facet joint tropism is higher in the patients with spondylolysis, suggesting that facet tropism seems to play a role in the etiology of spondylolysis as a predisposing factor.

Keywords: Facet joint; spondylolysis; tropism; young adult.

Developmental defect in pars interarticularis, articulation between the upper and lower vertebrae in lower lumbar spine, can be seen approximately in $5 \%$ of young adults. ${ }^{[1]}$ Spondylolysis is the unilateral or bilateral stress fracture of this region due to hypermobility-induced overloading caused by this defect. ${ }^{[1,2]}$ Predisposing factors include family history, repetitive microtraumas, and lumbar hyperlordosis. ${ }^{[2]}$

The facet joints account for $16 \%$ of the total vertical load in spine. ${ }^{[3-5]}$ Standard value $(\mathrm{SV})$ is the mean difference between the bilateral facet joint angle (FJA) measurements. Standard value measurements greater than $6^{\circ}$ indicates facet asymmetry and is referred as facet tropism. ${ }^{[6,7]}$ Facet asymmetry was first defined by Farfan and Sullivan ${ }^{[8]}$ in 1967, reporting that facet asymmetry was a predisposing factor for lumbar disc hernia development and coronal plan facet joint asymmetry increased the risk of disc herniation. Biomechanical studies have also shown that an increased shear force due to facet tropism is a

\section{Corresponding author: Ahmet Eroğlu, MD. Van Asker Hastanesi Nöroşirürji Kliniği, 65040 Van, Turkey. e-mail: drahmeteroglu@gmail.com}


potential risk for lumbar pain, lumbar disc hernia, and degenerative lumbar diseases. ${ }^{[5,9-11]}$

Asymmetry due to facet tropism may cause an impaired balance and non-homogenous load share in the repetitive lumbar movements. Increased mechanical stress may also lead to pars fractures, facilitating disc and facet joint degeneration. ${ }^{[2,4,5,12]}$ Wang and Yang ${ }^{[12]}$ demonstrated that aging and facet tropism led to facet joint coronalization by means of degenerative process, stress, and disc degeneration. Several studies have also shown that facet tropism is a predisposing factor including lumbar disc hernia, lumbar degenerative spondylolisthesis, facet osteoarthritis, and mechanical lumbar pain. ${ }^{[3,11,13,15]}$ There are several studies focusing on the effects of facet tropism in spondylolysis patients; however, the sample in these studies included older patients with degenerative disease. ${ }^{[1,4,14]}$ In the present study, therefore, we aimed to evaluate facet tropism in younger patients with lumbar spondylolysis and to investigate the role of facet tropism in the development of spondylolysis.

\section{PATIENTS AND METHODS}

\section{Patient group}

This case-control study was approved by the Research Ethics Committee of Van Training and Research Hospital (05.02.2016 - 2016/1). A written informed consent was obtained from each participant. The study was conducted in accordance with the principles of the Declaration of Helsinki.

Between February 2013 and December 2015, a total of 102 male patients with bilateral L5 pars defect were included in the study. Of these patients, 53 with lumbar pain for more than who were diagnosed with spondylolysis between the L5-S1 vertebrae using conventional X-ray and computed tomography (CT) findings were enrolled as the study group. The control group included 49 male patients who underwent abdominal CT examination for other pathologies in the emergency service or general surgery clinic and had no lumbar pathology based on the neurosurgical evaluation. Patients with a previous history of spondylolysis, lumbar disc hernia, lumbar trauma, scoliosis, discitis, or previous lumbar spine surgery were excluded.

\section{Facet joint angle measurement}

The patients with spondylolysis were evaluated with lumbar CT, while the control group was evaluated with abdominal CT. Visual data were obtained from 64 multi-slice CT (Brilliance, Philips, Oud-Beijerland, Holland) using a $3 \mathrm{~mm}$ slice width. Bilateral L3-4,
L4-5, and L5-S1 FJA were measured in the axial plane, as described by Noren et al. ${ }^{[15]}$ The reference plan (RP) was defined as the line passes in the mid-axis of intervertebral disc and spinous process base. The facet line (FL) was defined as the line passing between the anteromedial and posteromedial margin of the bilateral superior articular facet. The FJA is defined as the angle between RP and FL (Figure 1). Standard value (SV) and mean tropism angles were measured as described by Vanharanta et al. ${ }^{[16]}$ In our study, facet tropism was defined as the difference higher than $6^{\circ}$ (equals to $1 \mathrm{SV}$ ) in the bilateral FJA measurement. Differences in the FJA measurements were classified as follows: $<6^{\circ}=$ no tropism, $6^{\circ}-12^{\circ}=$ moderate tropism, and $>12^{\circ}=$ severe tropism.

Inter-observer variability was determined by calculating the interclass correlation coefficient (ICC). The ICC was calculated using a two-way mixed effects model. The individual ICC was 0.720 , indicating adequate reproducibility. Intra-observer variability was determined by calculating the ICC using a two-way

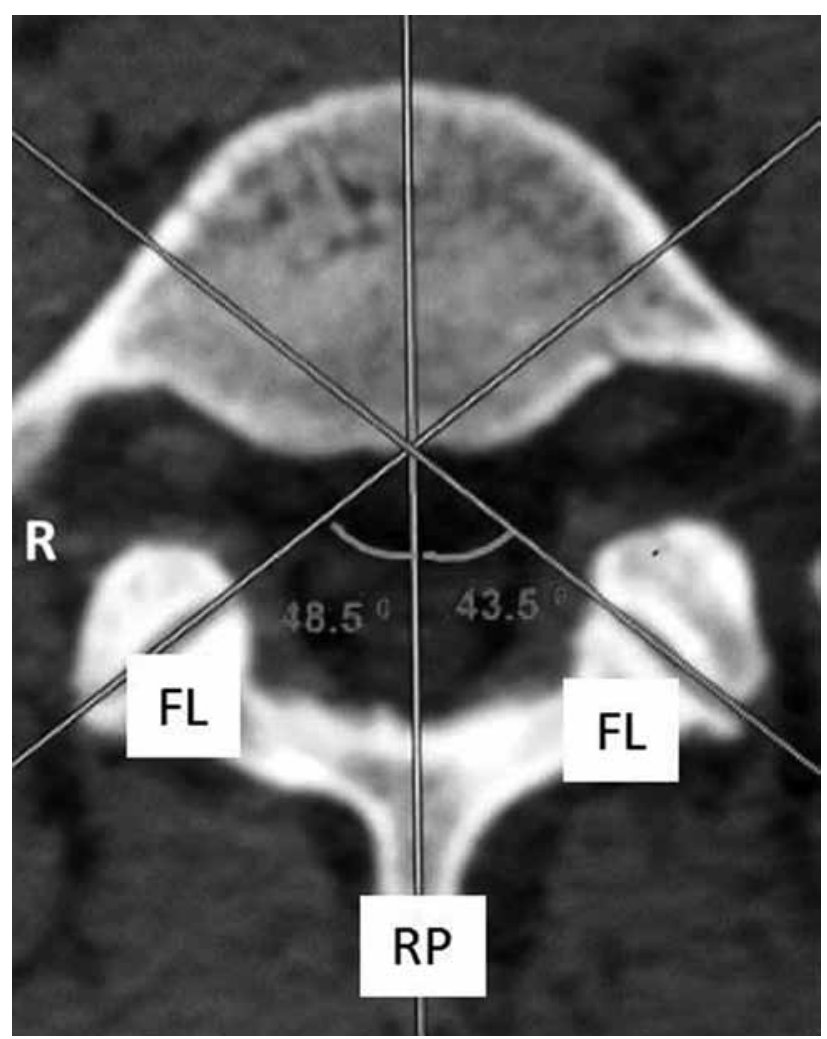

Figure 1. The reference plan (RP) is defined as the line passes in the mid-axis of intervertebral disc and spinous process basis. The facet line (FL) is defined as the line passes between anteromedial and posteromedial margin of the bilateral superior articular facet. The facet joint angle is defined as the angle between the RP and FL. 
mixed effects model. The individual ICCs for the first and second observer were 0.691 and 0.673 , respectively, indicating adequate reproducibility.

\section{Statistics analysis}

Power analysis was based on online DSS research calculator. Descriptive data were expressed in mean and standard deviation (SD). With an alpha error of 0.05 , power of the study was calculated as $98.6 \%$.

Statistical analysis was performed using SPSS version 15.0 software (SPSS Inc., Chicago, IL, USA). Continuous variables were expressed in mean value $\pm \mathrm{SD}$, while categorical variables were expressed in number and percentage. The Kolmogorov-Smirnov test was used to assess whether data were distributed normal. The Student's t-test was used to analyze significant differences between normally distributed continuous variables, while the Mann-Whitney U test was carried out to analyze significant differences between abnormally distributed continuous variables. Categorical variables were examined using the chi-square test. A $p$ value of $<0.05$ was considered statistically significant.

\section{RESULTS}

In this study, all participants were male with a mean age of $23.2 \pm 3.4$ (range: 20 to 27 ) years in patients with spondylolysis and 25.4 \pm 5.6 (range: 20 to 32 ) years in the control group, indicating no significant difference $(\mathrm{p}>0.05)$. A total of 318 FJA were measured in 53 patients with spondylolysis and 294 FJA were measured in 49 control subjects (total 612 FJA). L3-4 measurements in the spondylolysis group showed no tropism in $43.4 \%(\mathrm{n}=23)$, moderate tropism in $54.7 \%(\mathrm{n}=29)$, and severe tropism in $1.9 \%(\mathrm{n}=1)$. L4-5 measurements in spondylolysis group showed no tropism in $32.1 \%(\mathrm{n}=17)$, moderate tropism in $64.2 \%(\mathrm{n}=34)$, and severe tropism in $3.8 \%(\mathrm{n}=2) . \mathrm{L} 5-\mathrm{S} 1$ measurements in the spondylolysis group showed no tropism in $37.7 \%(\mathrm{n}=20)$, moderate tropism in $41.5 \%$ $(n=22)$, and severe tropism in 20.8\% $(n=11)$. L3-4 measurements in the control group showed no tropism in $87.8 \%(n=43)$, moderate tropism in $12.2 \%(n=6)$, and severe tropism in $0 \%(\mathrm{n}=0)$. L4-5 measurements in the control group showed no tropism in $79.6 \%(\mathrm{n}=39)$, moderate tropism in $20.4 \%(\mathrm{n}=10)$, and severe tropism in $0 \%(\mathrm{n}=0)$. L5-S1 measurements in the control group showed no tropism in $69.4 \%(\mathrm{n}=34)$, moderate tropism in $28.6 \%(\mathrm{n}=14)$, and severe tropism in $2.0 \%(\mathrm{n}=1)$ (Table 1). The mean FJA measurements were $32.9 \pm 5.1^{\circ}$ at L3-4 level, $37.5 \pm 5.4^{\circ}$ at L4-5 level, and $41.2 \pm 7.8^{\circ}$ at L5-S1 level in the spondylolysis group. In the control group, the mean FJA measurements were $33.2 \pm 5.7^{\circ}$ at L3-4 level, $39.7 \pm 4.9^{\circ}$ at L4-5 level, and $42.2 \pm 4.9^{\circ}$ at L5-S1 level (Table 2). Accordingly, in terms of

Table 1. Right and left facet joint angles, right and left facet joint angle differences, and facet tropism at L3-4, L4-5, and L5-S1 levels in spondylolysis and control groups

\begin{tabular}{|c|c|c|c|c|c|c|c|}
\hline & \multicolumn{3}{|c|}{ Spondylolysis group $(n=53)$} & \multicolumn{3}{|c|}{ Control group $(n=49)$} & \multirow[b]{2}{*}{$p$} \\
\hline & $\mathrm{n}$ & $\%$ & Mean \pm SD & $\mathrm{n}$ & $\%$ & Mean \pm SD & \\
\hline Right L3-4 facet angle (in degrees) & & & $32.0 \pm 5.9$ & & & $32.8 \pm 6.3$ & $0.481^{\star}$ \\
\hline Left L3-4 facet angle (in degrees) & & & $33.9 \pm 5.8$ & & & $33.6 \pm 6.3$ & $0.821^{*}$ \\
\hline L3-4 facet angle difference (in degrees) & & & $6.3 \pm 3.0$ & & & $3.5 \pm 2.1$ & $<0.001^{*}$ \\
\hline L3-4 tropism & & & & & & & $<0.001^{\star}$ \\
\hline None & 23 & 43.4 & & 43 & 87.8 & & \\
\hline Moderate & 29 & 54.7 & & 6 & 12.2 & & \\
\hline Severe & 1 & 1.9 & & 0 & 0 & & \\
\hline Right L4-5 facet angle (in degrees) & & & $36.5 \pm 6.1$ & & & $39.7 \pm 5.5$ & $0.060^{*}$ \\
\hline Left L4-5 facet angle (in degrees) & & & $38.5 \pm 7.3$ & & & $39.7 \pm 5.3$ & $0.346^{*}$ \\
\hline L4-5 facet angle difference (in degrees) & & & $7.4 \pm 3.0$ & & & $4.1 \pm 2.1$ & $<0.001^{*}$ \\
\hline L4-5 tropism & & & & & & & $<0.001^{* *}$ \\
\hline None & 17 & 32.1 & & 39 & 79.6 & & \\
\hline Moderate & 34 & 64.2 & & 10 & 20.4 & & \\
\hline Severe & 2 & 3.8 & & 0 & 0 & & \\
\hline Right L5-S1 facet angle (in degrees) & & & $38.8 \pm 8.7$ & & & $41.7 \pm 5.2$ & $0.052^{*}$ \\
\hline Left L5-S1 facet angle (in degrees) & & & $43.6 \pm 8.8$ & & & $42.7 \pm 6.2$ & $0.578^{\star}$ \\
\hline L5-S1 facet angle difference (in degrees) & & & $8.1 \pm 4.5$ & & & $5.2 \pm 3.0$ & $0.001^{*}$ \\
\hline L5-S1 topism & & & & & & & $0.001^{* *}$ \\
\hline None & 20 & 37.7 & & 34 & 69.4 & & \\
\hline Moderate & 22 & 41.5 & & 14 & 28.6 & & \\
\hline Severe & 11 & 20.8 & & 1 & 2.0 & & \\
\hline
\end{tabular}

SD: Standard deviation; ${ }^{*}$ Independent t-test; ${ }^{* *}$ Pearson chi-square test; Bold $p$ values $<0.05$. 
Table 2. Facet joint angle measurements in spondylolysis and control group according to levels

\begin{tabular}{lcccc}
\hline Level & Spondylolysis group & & Control group & \multirow{2}{*}{$p^{*}$} \\
\cline { 2 - 2 } & Mean \pm SD & & Mean \pm SD & \\
\hline L3-4 & $32.9 \pm 5.1$ & & $33.2 \pm 5.6$ & 0.872 \\
L4-5 & $37.5 \pm 5.4$ & & $39.7 \pm 4.8$ & 0.060 \\
L5-S1 & $41.2 \pm 7.7$ & & $42.2 \pm 4.9$ & 0.449 \\
\hline
\end{tabular}

SD: Standard deviation; ${ }^{*}$ Student's t-test.

L3-4, L4-5, and L5-S1 levels, there was no significant difference between the right and left mean FJA in both groups $(p>0.05)$. The frequency of facet tropism and difference between the right and left FJA at all three levels (L3-4, L4-5, and L5-S1) were significantly higher in the spondylolysis group than the control group $(\mathrm{p}<0.05)$. Although there was no significant difference in the differences $(p>0.05)$, the mean FJA were getting significantly higher $(p<0.05)$ in lower levels for both groups. In addition, facet tropism at L5-S1 level was significantly more frequent than facet tropism at L3-4 level $(\mathrm{p}<0.001)$ (Table 1$)$.

\section{DISCUSSION}

Facet joints play a major role in flexion, extension, and rotational movements of the spine. Facet joint tropism is the asymmetry between the right and left FJA of the same vertebra. ${ }^{[4,5,17,18]}$ Facet joint asymmetry is uncommon, and 10 to $70.5 \%$ of cases are elderly in the general population. ${ }^{[4,14]}$

Several criteria are defined for facet tropism. Noren et al. ${ }^{[15]}$ defined facet tropism as the differences higher than $5^{\circ}$ between bilateral FJA. A difference higher than 1 to $10^{\circ}$ or $1 \mathrm{SV}$ between the FJA indicates facet tropism in two other biomechanical studies. ${ }^{[5,14]}$ In addition, Wang and $\mathrm{Zhou}^{[3]}$ calculated SD equals to $10^{\circ}$ in their study. Differences between bilateral FJA smaller than $10^{\circ}$ indicate no tropism and higher than $10^{\circ}$ indicates tropism. Grogan et al. ${ }^{[19]}$ found $1 \mathrm{SV}$ equals to $7^{\circ}$ and classified facet tropism in three stages: no tropism (bilateral FJA difference $<7^{\circ}$ or $<1 \mathrm{SV}$ ), moderate tropism $\left(7-15^{\circ}\right.$ or $\left.1-2 \mathrm{SV}\right)$, and severe tropism $\left(>15^{\circ}\right.$ or $>2 \mathrm{SV}$ ). In our study, we found $1 \mathrm{SV}$ equals to $6^{\circ}$ and FJA differences $<6^{\circ}$ indicated no tropism, $6-12^{\circ}$ moderate tropism, and $>12^{\circ}$ severe tropism.

The relationship between the facet joint's morphological properties and lumbar degenerative lesions has not been defined clearly, yet..$^{[4,9,11,20]}$ Although the link between facet tropism and lumbar disc hernia, lumbar spondylolysis, and degenerative spondylolisthesis was reported previously, ${ }^{[3,10,21]}$ other studies failed to show the correlation between facet tropism and lumbar degenerative lesions. ${ }^{[12,19]}$

Degenerative process in spine due to aging is inevitable and starts in the second decade of life. ${ }^{[1,4,7]}$ Spondylolysis usually occurs during adolescence. Load in neural arc increases from L1 down to L5 vertebra with flexion and extension movements. Coronal positioning of the facet joints at L5 level and facet tropism may lead to pars fractures due to overload with repetitive sagittal movements. ${ }^{[1]}$ Pars defects usually occur at L5 level in patients with spondylolysis. ${ }^{[1,6]}$ Several studies have shown a possible relationship between facet tropism and development of spondylotic defects. ${ }^{[2,7]}$ Another opinion is that the coronal positioning of pars interarticularis, which has a strong link to sacral and lumbar articular processes, may cause stress with micromotions and, thus, facilitates the development of spondylolysis. $^{[6]}$

On the other hand, Kalichman et al. ${ }^{[1]}$ found no relationship between spondylolysis and facet tropism or facet orientation. However, Williams et al. ${ }^{[21]}$ reported that facet tropism at L5-S1 level had a direct effect on degeneration in their multi-center, ethnic study including 371 patients. On the contrary, Grogan et al. ${ }^{[19]}$ found no correlation between facet tropism and facet joint degeneration in their study. The authors found facet tropism in 10 of 104 lumbar FJA measurements at L3-4 and L5-S1 levels. However, the results of the aforementioned study was controversial, as the number of samples examined was low (21 cadavers) and FJA at L4-5 level, which is critical for joint tropism due to increased mobility and high rate of degeneration, were unable to be measured. In our study, 612 FJA at L3-4, L4-5, and L5-S1 levels of a total of 102 patients were measured.

Pichaisak et al ${ }^{[14]}$ conducted a study to examine the effects of facet tropism on 120 patients (60 patients with lumbar degenerative spondylosis and 60 patients in the control group). The authors measured L3-4, L4-5, and L5-S1 FJA bilaterally using magnetic resonance imaging (MRI) and found that facet tropism was significantly higher at L4-5 level in the lumbar degenerative spondylosis group than the control group. In another study, Masharawi et al. ${ }^{[2]}$ used threedimensional imaging for the FJA measurements and searched for facet tropism in patients with bilateral L5 spondylolysis. The authors detected facet tropism at L5-S1 level in the coronal plane and measured the mean tropism angle higher than $13^{\circ}$. In addition, Wang and $\mathrm{Zhou}^{[3]}$ reported that facet tropism was significantly higher at L4-5 and L5-S1 levels in young 
adolescents with lumbar discopathy than the control group. Don and Robertson ${ }^{[6]}$ measured the FJA in the patients with spondylolysis at L3-4, L4-5, and L5-S1 levels using MRI and found coronalization at L5-S1 level, where pars defect occurs. In the present study, we also found higher coronalization rates at L5-S1 level in the spondylolysis group, compared to the FJA in the upper levels.

The mean age of the patients was 47.9, 44.5, 46.7, and 43.5 years in the study of Masharawi et al., ${ }^{[2]}$ Don and Robertson ${ }^{[7]}$ Kalichman et al., ${ }^{[1]}$ and Pichaisak et al., ${ }^{[14]}$ respectively. In our study, the mean age was 23.2 years in the spondylolysis group and 25.4 years in the control group. To the best of our knowledge, our study population is the youngest in the literature.

Furthermore, Masharawi et al. ${ }^{[2]}$ calculated the mean FJA as $57^{\circ}$ on the right side and as $56^{\circ}$ on the left side at L5 in the spondylolysis patients with coronallypositioned facet joints. We calculated the mean FJA as $38.7^{\circ}$ on the right side and as $43.5^{\circ}$ on the left side at L5 level in our study. This difference can be attributed to minimal degenerative changes and less coronal positioning in the facet joints in younger patients.

The most recent literature about the effects of facet tropism on spondylolysis, lumbar discopathy, and lumbar degenerative disease has demonstrated that the FJA and facet joint coronal positioning increases at lower levels, the rate of facet asymmetry is higher at the levels with pars defect, and facet tropism is most commonly seen at L5-S1 than L4-5 level. ${ }^{[3,10,11]}$ Consistent with these findings, we also found that the FJA measurements and rate of facet tropism were higher; coronalization in facet was seen more often and more severe; vertical overloading and increased FJA increased the stress at this level; and facet tropism played a predisposing role in the development of spondylolysis joint as much more common at L5 level than at L5-S1 level, where pars defects occur commonly. In our study, the facet joints were more in coronal positioning with an increased rate off facet tropism in the patients with spondylolysis.

On the other hand, the present study has some limitations including small sample size with only young population and lack of female subjects, as this study was conducted in a military hospital. A potential bias would have ensued due to the fact that since severe tropism in the control group was seen in only one case at only one level, the reliability of the chi-square test may be controversial for the control group. Nevertheless, the results appear to be significant.
In conclusion, facet joint morphology has been widely questioned as being an etiologic factor for degenerative spine diseases. Based on our study results indicating higher rates of facet tropism in the patients with spondylolysis, facet joint tropism appears to be an important predisposing factor in the development of spondylolysis.

\section{Declaration of conflicting interests}

The authors declared no conflicts of interest with respect to the authorship and/or publication of this article.

\section{Funding}

The authors received no financial support for the research and/or authorship of this article.

\section{REFERENCES}

1. Kalichman L, Guermazi A, Li L, Hunter DJ, Suri P. Facet orientation and tropism: associations with spondylolysis. J Spinal Disord Tech 2010;23:101-5.

2. Masharawi YM, Alperovitch-Najenson D, Steinberg N, Dar G, Peleg S, Rothschild B, et al. Lumbar facet orientation in spondylolysis: a skeletal study. Spine (Phila $\mathrm{Pa}$ 1976) 2007;32:176-80.

3. Wang H, Zhou Y. Facet tropism: possible role in the pathology of lumbar disc herniation in adolescents. J Neurosurg Pediatr 2016;18:111-5.

4. Matsuo Y, Kaito T, Iwasaki M, Sugiura T, Fujimori T, Nagamoto $Y$, et al. 3D morphometric analysis of laminae and facet joints in patients with degenerative spondylolisthesis. Mod Rheumatol 2015;25:756-60.

5. Schleich C, Müller-Lutz A, Blum K, Boos J, Bittersohl B, Schmitt $B$, et al. Facet tropism and facet joint orientation: risk factors for the development of early biochemical alterations of lumbar intervertebral discs. Osteoarthritis Cartilage 2016;24:1761-8.

6. Ward CV, Latimer B. Human evolution and the development of spondylolysis. Spine (Phila Pa 1976) 2005;30:1808-14.

7. Don AS, Robertson PA. Facet joint orientation in spondylolysis and isthmic spondylolisthesis. J Spinal Disord Tech 2008;21:112-5.

8. Farfan HF, Sullivan JD. The relation of facet orientation to intervertebral disc failure. Can J Surg 1967;10:179-85.

9. Jaumard NV, Welch WC, Winkelstein BA. Spinal facet joint biomechanics and mechanotransduction in normal, injury and degenerative conditions. J Biomech Eng 2011;133:071010.

10. Kim HJ, Kang KT, Son J, Lee CK, Chang BS, Yeom JS. The influence of facet joint orientation and tropism on the stress at the adjacent segment after lumbar fusion surgery: a biomechanical analysis. Spine J 2015;15:1841-7.

11. Wang $\mathrm{H}$, Zhang $\mathrm{Z}$, Zhou Y. Irregular Alteration of Facet Orientation in Lumbar Segments: Possible Role in Pathology of Lumbar Disc Herniation in Adolescents. World Neurosurg 2016;86:321-7.

12. Wang J, Yang X. Age-related changes in the orientation of lumbar facet joints. Spine (Phila Pa 1976) 2009;34:596-8. 
13. Do DH, Taghavi CE, Fong W, Kong MH, Morishita Y, Wang JC. The relationship between degree of facet tropism and amount of dynamic disc bulge in lumbar spine of patients symptomatic for low back pain. Eur Spine J 2011;20:71-8.

14. Pichaisak W, Chotiyarnwong C, Chotiyarnwong P. Facet joint orientation and tropism in lumbar degenerative disc disease and spondylolisthesis. J Med Assoc Thai 2015;98:373-9.

15. Noren R, Trafimow J, Andersson GB, Huckman MS. The role of facet joint tropism and facet angle in disc degeneration. Spine (Phila Pa 1976) 1991;16:530-2.

16. Vanharanta H, Floyd T, Ohnmeiss DD, Hochschuler SH, Guyer RD. The relationship of facet tropism to degenerative disc disease. Spine (Phila Pa 1976) 1993;18:1000-5.

17. Chadha M, Sharma G, Arora SS, Kochar V. Association of facet tropism with lumbar disc herniation. Eur Spine J 2013;22:1045-52.

18. Ening G, Kowoll A, Stricker I, Schmieder K, Brenke C.
Lumbar juxta-facet joint cysts in association with facet joint orientation, -tropism and -arthritis: A case-control study. Clin Neurol Neurosurg 2015;139:278-81.

19. Grogan J, Nowicki BH, Schmidt TA, Haughton VM. Lumbar facet joint tropism does not accelerate degeneration of the facet joints. AJNR Am J Neuroradiol 1997;18:1325-9.

20. Kim HJ, Chun HJ, Lee HM, Kang KT, Lee CK, Chang BS, et al. The biomechanical influence of the facet joint orientation and the facet tropism in the lumbar spine. Spine J 2013;13:1301-8.

21. Williams R, Cheung J, Goss B, Rajasekaran S, Kawaguchi Y, Acharya S, et al. An International Multicenter Study Assessing the Role of Ethnicity on Variation of Lumbar Facet Joint Orientation and the Occurrence of Degenerative Spondylolisthesis in Asia Pacific: A Study from the AO Spine Asia Pacific Research Collaboration Consortium. Global Spine J 2016;6:35. 